\title{
Uma obra pioneira
}

MARIA ARMINDA DO NASCIMENTO ARRUDA

Cor, Profissao e Mobilidade: O Negro e o Rádio de Sao Paulo, livro de autoria do antropólogo João Baptista Borges Pereira, inscreve-se no rol das obras que conseguem preservar vivacidade, a despeito do tempo. Transcorridos mais de trinta anos desde a primeira edição em 1967, o tex to resguarda os atributos de reflexão afinada com a melhor tradição das ciências sociais no Brasil, especialmente do estilo que tipificou o modo de construção das análises da chamada “Escola Sociológica Paulista”. É visível no andamento reflexivo a presença das preocupações dominantes e características das ciências sociais que vicejaram na Universidade de São Paulo: o tema do negro e das relações sociais; o tratamento daestrutura social. Nesse sentido preciso, a reflexão realizada é tributária de um veio inau-
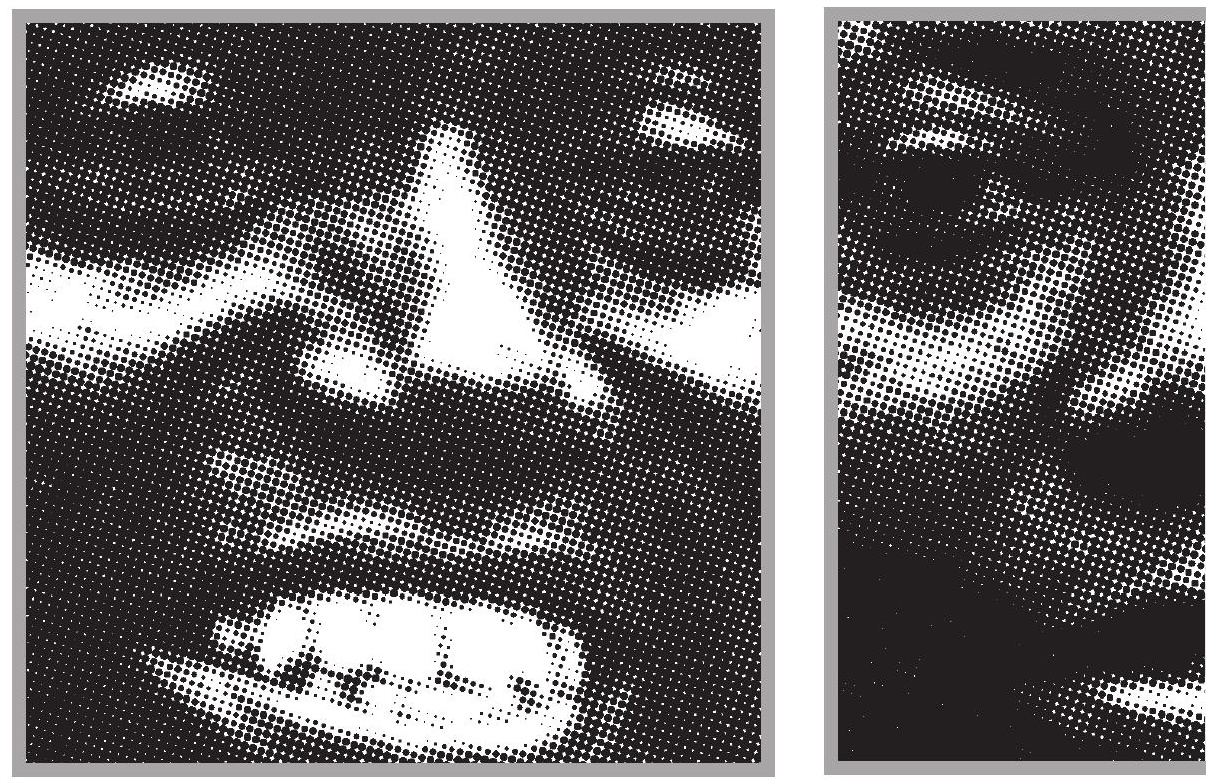
gurado pela pesquisa sobre relações raciais no Brasil, promovida pela Unesco no início do decênio de 1950, cujos responsáveis para o caso paulista foram Roger Bastide e Florestan Fernandes. Olivro, no entanto, encerra certas particularidades que o singularizam no âmbito do pensamento então em voga e que se manifestam em três vertentes fundamentais: na circunscrição do objeto de análise; na combinação de uma análise micro e macrossociológica; na consideração simultânea de questões pertinentes à estrutura social e ao domínio da cultura. 


\section{MARIA ARMINDA \\ DO NASCIMENTO}

ARRUDA é professora do Departamento de

Sociologia da FFLCH-USP e

autora de, entre outros,

Mitologia da Mineiridade.

O Imaginário Mineiro na

Vida Política e Cultural do

Brasil(Brasiliense).

Cor, Profissão e Mobilidade:

O Negro e o Rádio de São

Paulo, de João Baptista

Borges Pereira, São Paulo,

Edusp, 2001.
É significativa a opção por enfocar o problema da mobilidade social dos negros e mulatos na sociedade brasileira do período e, particularmente, em São Paulo, elegendo o rádio como meio privilegiado para desenvolver a pesquisa. $\mathrm{O}$ autor esclarece que

"a escolha da esfera radiofônica para o campo desta análise nada tem de arbitrária ou acidental. Experiências do dia-a-dia testemunham com eloqüência que na sociedade brasileira, ou em suas variantes mais urbanizadas, há pelo menos duas dimensões onde o homem de cor parece gozar de condições

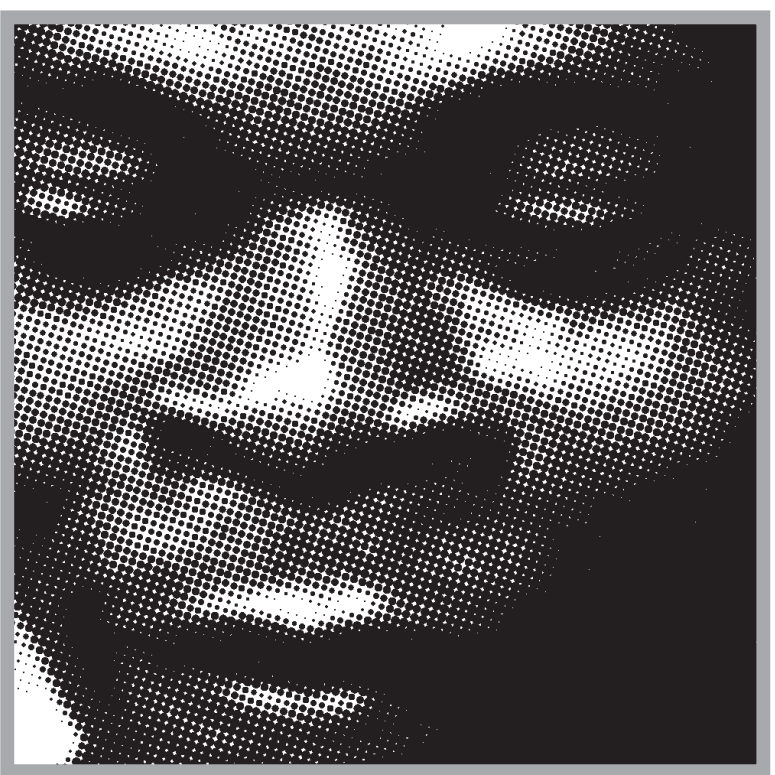

peculiares, diferentes daquelas comumente observadas nas demais esferas de atividades das quais participam brancos e pretos. Referimo-nos ao rádio e ao futebol" (p. 36).

Trata-se, então, de dimensionar os processos de mobilidade social ascendente dos negros à luz da criação de oportunidades novas que se abrem, inquirindo, concomitantemente, sobre as

condições efetivas dos descendentes dos escravos de vivenciar situações semelhantes aos brancos num meio social mais plástico à absorção dos homens de cor. O que está em tela são ocorrências interativas entre negros e brancos propícias às expressões de preconceito. Daí, a análise combinar permanentemente reflexões que buscam aquilatar a integração social dos negros e avaliar a realidade da sua assimilação, exigindo do autor tratar ao mesmo tempo de processos sociais e culturais. "Com respeito ao contingente de cor, este duplo ponto de vista propiciou-nos encarar o negro simultaneamen- 
te como categoria social e "racial"' (p. 28).

$\mathrm{O}$ rádio afigura-se, desse modo, como um microcosmo do desenvolvimento das relações raciais no país, num milieu propício à emergência de contatos sociais construídos segundo os padrões de uma sociedade em mudança. No caso específico, as transformações no campo musical provocadas pela consagração do samba como gênero tipicamente brasileiro, desalojando as outras tradições, combinaram-se ao amplo poder de difusão do rádio apoiado na modernização do veículo. Predomina, assim, uma percepção inicial favorável às relações entre brancos e negros, deixando a entrever que a perspectiva orientadora da reflexão nutria-se no solo das esperanças de mudança. A aposta, no entanto, perece guardar ceticismo característico daquelas atitudes de reserva que não avançam sem o conhecimento detido do terreno, obtido por meio de pesquisa minuciosa - na qual se combinaram instrumentos diferenciados de coleta do material (entrevistas formais e informais, histórias de vida, observação-participante, dados quantitativos) - precedida de survey realizado com o objetivo de afinar as técnicas utilizadas.

Essa atitude de cautela frente ao reconhecimento de que o país atravessava um momento de transformações amplas reproduzia o clima dominante entre os cientistas sociais da Universidade de São Paulo, que preservaram um certo recolhimento diante das atitudes mais aderentes às visões otimistas sobre a construção do que Florestan Fernandes denominava de "suporte de civilização moderna”, expressão significativamente cunhada no decorrer das suas análises sobre a condição dos descendentes dos escravos. Cor, Profissao e Mobilidade é obra que brotou em ambiente intelectual responsável também pelo aparecimento de A Integraçao do Negro na Sociedade de Classes, pois ambas foram escritas no mesmo período e compartilharam, no fim da análise, da mesma postura cética a respeito da situação social das pessoas de cor no Brasil, ainda que tivessem partido de concepções que não abjuravam in totum as possibilidades de mudanças no destino dos negros e dos mulatos. A construção de duas hipóteses suplementares de trabalho parece derivar da atitude inicial: "a primeira, ligada ao engajamento profissional do negro ao novo campo de atividades remuneradas; a segunda, associada aos processos de mobilidade" (p. 29). Dito de outro modo, as hipóteses refletem as esperanças de transformação na vida do contingente de cor, exprimindo os vínculos entre conhecimento e ação, isto é, a existência daquela postura classicamente assumida de que só pode pensar algo sociologicamente quem quer algo socialmente.

A reflexão, nesse sentido, persegue as manifestações de integração e de assimilação dos negros, embora o andamento analítico exponha os impasses da condição e as desesperanças vivenciadas no transcurso da ascensão. O processo de mobilidade social dos negros ocorre de modo particular, pois

"o indivíduo que se destaca da massa negra é confusamente julgado, ora através das suas características 'raciais', ora através de suas conquistas econômico-sociais. Tal ambigüidade não reflete tão-somente a existência de esquema contraditório de padrões, que age paralela e simultaneamente compondo uma imagem imprecisa do homem de cor e colocando-o perplexo diante de si mesmo e da situação onde se encontra; o que é mais desconcertante tanto para os que vivem a situação como para os que a estudam - é que essa ambigüidade deixa entrever a existência de um mecanismo incoerente de atribuição de status, por meio do qual o 'racial', ainda que mutilando consideravelmente as alternativas de participação do negro na sociedade global, deixa-lhe franqueadas certas áreas, onde a ação do peneiramento cabe, com prioridade, aos fatores extraraciais. Surgindo aqui e eclipsando ali, revigorada acolá e abrandada além, a linha de cor segmenta de maneira suigeneris o campo sociocultural, configurando uma realidade desordenada e desorientadora para aqueles que a vivem, o que 
levou um artista negro a confessar que 'preto que sobe vive como 'barata tonta', sem saber onde pisar; vive aos gomos, repartido em fatias"” (pp. 235-6).

A despeito da ascensão, o negro não consegue compor os traços integrados de sua identidade. A vivência de uma cisão provocada, de um lado, pelo desprendimento do seu mundo de origem e, de outro, pela experiência da discriminação, reforça o isolamento das pessoas de cor, tornando-as figuras sem lugar demarcado: "vivem, enfim, num relativo estado de atomização, não chegando, a rigor, a constituir uma camada social definida" (p. 248).

O caráter eminentemente sociológico do argumento emerge da perspectiva orientadora da reflexão. A dificuldade de construção de um lugar social preciso para os negros ascendidos deriva da presença de atitudes discriminatórias, acrescidas, no caso específico, de estereótipos ligados à profissão, o que impõe a análise das questões culturais, sem a qual não se viabiliza o tratamento do problema da identidade. Desse modo, entrelaçam-se as vertentes sociológica e antropológica no livro - uma vez que a indefinição social, coletivamente partilhada, cria obstáculos à construção identitária - que, simultaneamente, não propiciam a inclusão em posições correntes da estrutura social. Diferentemente do branco, o negro-radialista não consegue, por isso, contornar "os efeitos negativos da condição profissional... Ao chegar a essa fase, ele pára, sem maiores perspectivas. E aquelas alternativas que poderiam ser utilizadas para amenizar as representações em torno de sua profissão não se reproduzem, sob restrições que emergem de sua condição de homem de cor" (p. 251). As resistências presentes são desdobramentos de fatores oriundos da ordem racial vividos individualmente, ainda que sejam produtos coletivos.

Nesse andamento analítico, combinamse as inferências de natureza micro e macrossociológica, destacando-se o caráter atual da obra, preservado apesar dos anos. Nesse campo, o antropólogo trabalha com as auto-interpretações do negro-radialista a respeito da sua condição diversa daquela típica da massa de cor, apontando para as distinções existentes entre os recém-incorporados ao rádio e os veteranos. Os primeiros tendem a projetar um mundo de conquistas, construído por visões otimistas que identificam enriquecimento a branqueamento; os segundos estão imersos numa atmosfera de desilusão, compondo uma "particular filosofia de desencanto", sentimento "dos que se vêem traídos nas suas mais caras perspectivas". O arremate da reflexão reproduz uma postura de ceticismo, a despeito da pergunta que orientou a análise:

“A interrogação que se formula como ponto inicial para a sistematização dessas considerações busca saber em que medida o êxito no campo-artístico profissional propicia ao negro pleno acesso àquela constelação de oportunidades - sociais e culturais -que decorrem da carreira que adotou" (p. 237).

No registro da questão proposta no princípio, encontram-se inquietações que reverberam posições teórico-metodológicas enleadas nas visões do autor sobre a problemática social dos negros no Brasil. O privilegiamento das vivências concretas dos sujeitos envolvidos resultou na construção de um quadro vivo, composto de figuras moldadas em existências mescladas de esperanças e desenganos. Nada mais humano. Este livro ainda se singulariza pela eleição de um objeto de estudo que não havia sido considerado de modo sistemático pelos cientistas sociais: a condição social do negro apreendida a partir das oportunidades criadas no meio radiofônico. Essa particular combinação cristalizou-se na composição de uma obra pioneira que, como observou Roger Bastide em carta dirigida ao autor e reproduzida nessa edição, "abre um novo caminho e propõe novas abordagens". 